\title{
PERCEPÇÃO DO USUÁRIO DA ESTRATÉGIA SAÚDE DA FAMÍLIA SOBRE A FUNÇÃO DO ENFERMEIRO
}

\author{
Roniélha Moreira dos Santos ${ }^{1}$, Liliane da Consolação Campos Ribeiro ${ }^{2}$
}

RESUMO: A Enfermagem em Atenção Primária vem conquistando espaços e se estruturando juntamente com a Estratégia Saúde da Família (ESF). Este estudo, do tipo exploratório, descritivo e de abordagem qualitativa, teve por objetivos identificar e analisar a percepção que usuários de ESF têm da função do enfermeiro; os dados foram coletados por meio de entrevistas semidirigidas e categorizados utilizando-se a técnica de Análise de Conteúdo proposta por Bardin. Após a análise, emergiram as categorias temáticas: Reconhecimento da identidade do enfermeiro; Desconhecimento do real trabalho do enfermeiro; Assistência curativa e individual; e Figura benevolente. A pesquisa subsidiou a compreensão do trabalho do enfermeiro na percepção dos usuários da ESF, caracterizado pela assistência curativa e individual, evidenciando a necessidade de reorientação de seu trabalho.

PALAVRAS-CHAVE: Programa saúde da família; Enfermagem; Percepção.

\section{PERCEPTION OF THE FAMILY HEALTH STRATEGY USERS ON THE ROLE OF NURSES}

\begin{abstract}
Nurses in Primary Care are conquering space and structuring themselves along with the Family Health Strategy (FHS). This study has an exploratory, descriptive and qualitative approach, and its aim is to identify and analyze the perception that users of the FHS have on the nurses' role. Data were collected through semi-directed form and they were categorized using the technique of content analysis proposed by Bardin. Themes that emerged after analysis: knowing the identity of the nurse, misunderstanding of the actual work of nurses, curative and individual assistance, and benevolent figure. The research supported the understanding of nursing work on the FHS users' perception, characterized by individual and curative care, highlighting the need to redirect their work.
\end{abstract}

KEYWORDS: Family health program; Nursing; Perception.

\section{PERCEPCIÓN DEL USUARIO DE LA ESTRATEGIA SALUD DE LA FAMILIA ACERCA DE LA FUNCIÓN DEL ENFERMERO}

RESUMEN: La enfermería en Atención Primaria tiene conquistado espacios y se estructurado con la Estrategia Salud de la Familia (ESF). Este estudio, del tipo exploratorio, descriptivo y de abordaje cualitativo, tiene el objetivo de identificar y analizar la percepción que usuarios de ESF tienen de la función del enfermero. Los datos fueron recogidos por medio de entrevistas semiconducidas y categorizados utilizándose la técnica de Análisis de Contenido propuesta por Bardin. Del análisis, surgieron las siguientes categorías temáticas: Reconocimiento de la identidade del enfermero; Desconocimiento del real trabajo del enfermero; Asistencia curativa e individual; y Figura benevolente. La investigación ha subsidiado la comprensión del trabajo del enfermero en la percepción de los usuarios de la ESF, caracterizada por la asistencia curativa e individual, evidenciando la necesidad de reorientar su trabajo.

PALABRAS CLAVE: Programa salud de la familia; Enfermería; Percepción.

${ }^{1}$ Enfermeira do Programa Estratégia Saúde da Família da Secretaria Municipal de São Geraldo/MG.

${ }^{2}$ Enfermeira. Doutor em Enfermagem. Professor Assistente do Departamento de Enfermagem da Universidade Federal dos Vales do Jequitinhonha e Mucuri-UFVJM. Bolsista CNPq.

\section{Autor correspondente:}

Liliane da Consolação Campos Ribeiro

Universidade Federal dos Vales do Jequitinhonha e Mucuri

Rua da Glória, 187 - 39100-000 - Diamantina-MG-Brasil

Recebido: 29/04/10

E-mail: lilianeribeiro@hotmail.com

Aprovado: 20/09/10 


\section{INTRODUÇÃO}

Em 1988, com a promulgação da Constituição Brasileira, a saúde no país recebeu uma nova configuração, passando a ser um

\begin{abstract}
direito de todos e dever do estado, garantido mediante políticas sociais e econômicas que visem à redução do risco de doença e de outros agravos e ao acesso universal e igualitário às ações e serviços para sua promoção, proteção e recuperação ${ }^{(1: 33)}$.
\end{abstract}

Nesse sentido, foi idealizado o Sistema Único de Saúde (SUS), que já vinha sendo proposto no Movimento de Reforma Sanitária, configurado na $8^{\mathrm{a}}$ Conferência Nacional de Saúde e que se baseia nos princípios doutrinários da universalidade, equidade e integralidade. A partir daí, várias iniciativas institucionais legais foram criadas no intuito de viabilizar a proposta de direito à saúde, preconizada pela Constituição Federal.

Uma dessas iniciativas foi o Programa Saúde da Família, criado pelo Ministério da Saúde em 1994, e tendo como um dos objetivos ampliar a atuação do Programa dos Agentes Comunitários de Saúde (PACS), iniciado em 1991. Constituiu-se uma parceria de trabalho, na qual um programa interagiria com o outro, de forma complementar e facilitadora de ações ${ }^{(2)}$, a fim de orientar a organização da Atenção Básica no país e no sentido de garantir os princípios de territorialização, longitudinalidade no cuidado, intersetorialidade, descentralização, corresponsabilização e equidade. Nos primeiros anos, permaneceu a denominação de Programa Saúde da Família e, posteriormente, em sua fase de consolidação, veio a ser chamado de Estratégia Saúde da Família (ESF) ${ }^{(3)}$. Esse novo modelo de assistência decorre da necessidade de mudança do modelo hospitalocêntrico, o qual já não atendia as necessidade em saúde da sociedade brasileira. Com o intuito de rever paradigmas a ESF prioriza as ações de promoção, proteção e recuperação da saúde das pessoas e das famílias, de forma integral e contínua ${ }^{(4)}$.

Sob esse aspecto, a ESF faz com que a família passe a ser o principal foco de atenção, entendida e considerada a partir do ambiente onde vive. E é nesse espaço que se constroem as relações, dentro e fora do seio familiar, e onde se efetivam ações pela melhoria das condições de vida - permitindo, ainda, uma compreensão ampliada do processo saúde/doença, cuidando-se do indivíduo como um ser social e, portanto, utilizando-se de intervenções de maior impacto e significação comunitária.

O processo de trabalho na ESF é voltado para as ações desenvolvidas em equipe. Segundo o Ministério da Saúde, esta deve ser constituída por médico, enfermeiro, cirurgião-dentista, técnico de higiene dental (THD), auxiliar de consultório dentário (ACD), auxiliar ou técnico de enfermagem e agentes comunitários de saúde $(\mathrm{ACS})^{(5)}$.

A ESF é um importante mercado de trabalho para profissionais de enfermagem no país, e sua atuação vem se consolidando na prática e na experiência adquirida em Saúde Coletiva ${ }^{(2)}$. Entendemos, então, que os profissionais de enfermagem, para atuar na ESF, deverão incorporar alguns conceitos aplicáveis ao processo de trabalho no setor saúde, na qualidade de membro da equipe de uma unidade produtora de serviços de saúde, responsável por uma demanda social de uma área adscrita ${ }^{(6)}$. Desta forma, sua prática passa por uma série de transformações, deslocando a sua atuação predominantemente curativa, individualizada e vinculada às instituições hospitalares para a produção de serviços em unidades básicas de saúde, com ênfase nas ações de promoção e prevenção em bases coletivas ${ }^{(6)}$.

Algumas atividades atribuídas pelo Ministério da Saúde ${ }^{(5)}$ ao enfermeiro da ESF são:

- Realizar assistência integral a indivíduos e famílias na Unidade de Saúde da Família (USF) e, quando indicado ou necessário, no domicílio e/ ou demais espaços comunitários, como escolas e associações, em todas as fases do desenvolvimento humano;

- Conforme protocolos ou outras normativas técnicas estabelecidas pelo gestor municipal ou do Distrito Federal, observadas as disposições legais da profissão, realizar consulta de enfermagem, solicitar exames complementares e prescrever medicações;

- Planejar, gerenciar, coordenar e avaliar as ações desenvolvidas pelos ACS;

- Supervisionar, coordenar e realizar atividades de educação permanente a ACS e equipe de enfermagem;

- Contribuir e participar das atividades de educação permanente do auxiliar e técnico em enfermagem, ACD e THD;

- Participar do gerenciamento dos insumos necessários para o adequado funcionamento da USF. 
A inserção do enfermeiro na equipe de Saúde da Família promove a consolidação do vínculo deste profissional com a comunidade. Tal relação permite à equipe de enfermagem o desenvolvimento de ações efetivas na promoção da saúde da comunidade, uma vez que a aproxima do ambiente de convivência e das relações sociais do indivíduo.

Como foco de atenção da ESF, a família deve também ser compreendida como entidade pró-ativa no seu processo de saúde e construção social. Assim, acredita-se que a partir do usuário, é possível obter-se um conjunto de conceitos e atitudes relacionados à atenção recebida, com os quais se adquirem informações que beneficiam a organização dos serviços de saúde e usuários, ao serem atendidas as suas necessidades e perspectivas ${ }^{(7)}$. Além disso, num contexto local, ressalta-se a relevância de um processo de avaliação voltado para as expectativas dos próprios usuários, uma vez que estes são importantes parceiros da $\operatorname{ESF}^{(8)}$.

Diante do exposto, surgiram os seguintes questionamentos: Sob a ótica do usuário, quais atividades são desenvolvidas pelo enfermeiro da ESF ? O usuário é capaz de identificar quem é o enfermeiro nesta equipe? Para responder a tais questionamentos, decidiu-se pela realização deste estudo com o objetivo de identificar e analisar a percepção que usuários da ESF têm do processo de trabalho do enfermeiro.

\section{METODOLOGIA}

Trata-se de um estudo do tipo exploratório, descritivo, de abordagem qualitativa, o qual foi desenvolvido em USF do Município de Diamantina, Minas Gerais. O estudo foi previamente aprovado pelo Comitê de Ética em Pesquisa da Universidade Federal dos Vales do Jequitinhonha e Mucuri, registrado sob o número 052/08.

Definiu-se como critérios de inclusão na pesquisa ser residente na área de abrangência das USF por período igual ou superior a 2 anos, ter 18 anos de idade e aceitar participar do estudo. A escolha dos entrevistados foi aleatória, entre os usuários que procuravam espontaneamente a USF, com convite feito pela pesquisadora, respeitando-se a disponibilidade de tempo e aceitação em participar da pesquisa. Os participantes foram orientados quanto ao objetivo do trabalho e assinaram o Termo de Consentimento Livre e Esclarecido, respeitando-se os aspectos éticos e de confidencialidade preconizados pela Resolução
196/96 do Conselho Nacional de Saúde

Os dados foram obtidos por meio de entrevista semidirigida, aplicada a 11 usuários após consulta médica e/ou de enfermagem, uma vez que as pesquisas realizadas na USF após a consulta buscam resgatar a experiência concreta do usuário no serviço, evitando que este se esqueça das ações desenvolvidas durante a consulta, o que pode ocorrer após algum tempo ${ }^{(9)}$. $\mathrm{Na}$ definição desse número de participantes, considerou-se o critério de saturação dos dados, em que o pesquisador fecha o grupo de entrevistados quando, após as informações coletadas com certo número de sujeitos, as novas entrevistas passam a apresentar uma quantidade de repetições em seu conteúdo. Então, o pesquisador, entendendo que novas falas passam a ter acréscimos pouco significativos em vista dos objetivos inicialmente propostos para a pesquisa, decide encerrá-la ${ }^{(10)}$.

Os dados obtidos foram analisados conforme a Análise de Conteúdo proposta por Bardin, que pode ser entendida como

\begin{abstract}
um conjunto de técnicas de análise das comunicações visando obter, por procedimentos, sistemáticos e objetivos de descrição do conteúdo das mensagens, indicadores (quantitativos ou não) que permitam a inferência de conhecimentos relativos às condições de produção/ recepção (variáveis inferidas) destas mensagens ${ }^{(11: 42)}$.
\end{abstract}

Para a identificação das falas dos informantes/ usuários, preservando-se o anonimato, foram utilizadas as denominações "U1, U2 ... U11".

\section{RESULTADOS E DISCUSSÃO}

De acordo com os dados obtidos e submetidos à Análise de Conteúdo, foram eleitos alguns eixos temáticos relacionados aos usuários e à percepção que estes têm do processo de trabalho desenvolvido pelo enfermeiro da equipe de Saúde da Família.

\section{Caracterização dos sujeitos}

A faixa etária dos entrevistados variou entre 25 e 71 anos, predominando a de 36 a 60 anos (45\%), seguida pela de adultos jovens (25-35 anos), com 27 $\%$ dos respondentes, e acima de 60 (27\%). Pode-se observar a ampla heterogeneidade etária, sendo isso um dado favorável à obtenção de maior diversidade de opiniões, uma vez que as demandas e percepções sobre o serviço de saúde variam também com a faixa 
etária. Isso demonstra que as USF precisam estar preparadas para intervir na comunidade, lidando com diferentes fases do ciclo de vida familiar.

Dos entrevistados, 10 (91\%) eram do sexo feminino; a clientela predominantemente feminina retrata o cotidiano dos serviços de saúde brasileiros, especialmente os de Atenção Básica. Pode-se afirmar que a mulher é aquela que na maioria das vezes cuida dos afazeres domésticos e dos filhos, ficando sob sua responsabilidade a saúde da família, principalmente em cidades do interior, como é o caso do universo desta pesquisa. Nas regiões mais carentes de recursos de saúde, a oferta de serviços públicos tende a ser dirigida, de modo prioritário, à população maternoinfantil. Além dessa parcialidade das ações na Saúde da Família, em geral, os serviços formais funcionam em horários que coincidem com a jornada de trabalho, dificultando mais ainda o acesso da população inserida no mercado formal, em sua maior parte composta de indivíduos do sexo masculino ${ }^{(12)}$.

Apesar dessa referência da literatura ser do início da década de 90 , não houve grandes mudanças na população que mais recorre aos serviços de saúde. Estudos recentes demonstram que trabalhadores formais tendem a apresentar melhores condições de saúde, e nesse mercado da formalidade continua predominando o sexo masculino ${ }^{(13)}$.

Logo, as mulheres, configuram o outro lado da moeda - inseridas no mercado de trabalho informal, submetidas a dupla carga de trabalho (doméstico) - fazem maior uso dos serviços de saúde. Isso não quer dizer que o sexo masculino não apresente agravos em sua saúde. Há uma forte questão cultural envolvida nesse processo em que, no imaginário popular, homens são mais resistentes, sugerindo que as estratégias de saúde devam ser revistas de modo a ampliar a participação do homem nos serviços de saúde e no cuidado de $\mathrm{si}^{(14)}$.

O tempo de residência na área de abrangência da ESF variou entre 2 e 45 anos, com média de 15 anos. Este dado é de grande relevância, pois se acredita que quanto maior o tempo de residência em uma área de ESF, maior a probabilidade de o usuário ter utilizado os serviços da equipe e, consequentemente, ter contato com o enfermeiro da unidade e conhecimento sobre este assunto, para daí extrair sua percepção.

\section{Reconhecimento da identidade do enfermeiro}

A observação dos resultados revelou que, na maioria das vezes, os usuários sabem dizer quem é o enfermeiro da equipe de USF.

Em estudo de representações sociais sobre auto e hetero imagem realizado com 30 enfermeiros, foi identificada, a partir dos relatos destes profissionais, uma imagem de sobreposição aos demais membros da equipe de saúde. Eles destacaram a confusão, por parte da população, que considera o enfermeiro, em algumas situações, como médico e, em outras, como auxiliar ou técnico em enfermagem ${ }^{(15)}$; este resultado, portanto, se contrapõe à realidade encontrada no presente estudo.

Este resultado é de extrema relevância para a categoria profissional, uma vez que em sua história sempre estiveram presentes os equívocos quanto à sua identidade ${ }^{(15)}$. "As possibilidades do enfermeiro se manifestar como ser e trabalhador no cotidiano do trabalho estão intimamente relacionadas com a constituição de sua identidade"(16:53).

Contudo, dizer que os usuários souberam falar quem é o enfermeiro da ESF não significa, necessariamente, que eles reconhecem a identidade deste profissional.

A forma mais simples e habitual de alguém ser identificado é através do seu nome ${ }^{(17)}$, e isto pôde ser observado nas entrevistas. Entretanto, a identidade de alguém, no caso o enfermeiro, é um processo e não o produto; é a representação/ação e não essência, a natureza ou a substância. Assim, a identidade não é dada, mas vai se dando em contínuo processo de identificação ${ }^{(17)}$. Quando representamos um determinado papel, este é um fato social e não físico, na medida em que o significado do mesmo é compartilhado por um coletivo. Por exemplo: quando alguém é identificado como "enfermeiro"? Pode-se responder que é quando este se gradua em Enfermagem; esse dado, no entanto, assim considerado, ainda é um fato físico, e ser enfermeiro é um fato social.

Considerando-se o conceito de identidade aqui colocado, talvez os usuários não conseguiriam descrever em uma única resposta a identidade do enfermeiro da ESF. Mas o que se pretende questionar é: o que o enfermeiro representa dentro da equipe, sendo (re)conhecido apenas como "Fulano" ou como "enfermeiro", autor/ator de um processo social?

\section{Desconhecimento do real trabalho do enfermeiro}

Na ESF, o enfermeiro desempenha papel fundamental, pois cabe a ele o acompanhamento e 
supervisão do trabalho, a promoção das capacitações e educação continuada, além de atuar na assistência com ênfase na promoção da saúde ${ }^{(5)}$. Observou-se, nos resultados desta pesquisa, que os usuários sempre se referiam ao trabalho do enfermeiro da USF como sendo muito bom, sem defeitos. Contudo, não sabiam dizer quais atividades são desenvolvidas por este profissional. Atividades próprias do enfermeiro de ESF, como realizar consulta de enfermagem, solicitar exames complementares, prescrever medicações e coordenar o trabalho da equipe de enfermagem, quase não foram citadas, como demonstrado nas falas que se seguem:

Ah! Muitas atividades boas, né? De... de... sobre... esse negócio, de prevenção mesmo, né? Sobre esse negócio também que ela marca pra gente, né? Eu acho, né? (U3)

Uai, eu sei que ela tem muito trabalho, né? Mas eu não sei se tá certo. Tem caminhada... as agentes de saúde. É só isso que eu sei. (U8)

Cabe aqui uma ressalva: quando o usuário não sabe dizer o que o enfermeiro faz, isso não quer dizer, necessariamente, que este se exime de suas atribuições. Muitas questões hipotéticas podem estar aí implícitas: o entrevistado é um usuário pouco assíduo da ESF (o que atenua, mas não justifica, uma vez que o trabalho do enfermeiro de ESF não deve ser desenvolvido apenas dentro da USF), ou o enfermeiro desenvolve um trabalho mais burocrático do que assistencial, ficando assim distante do cliente, ou ainda o seu trabalho tem pouco destaque dentre os outros profissionais da equipe. Pode-se dizer que

o enfermeiro absorve tudo como sendo seu, sem uma especificidade de ação ou a delimitação de um papel próprio, o que tende a torná-lo invisível à instituição, à equipe de saúde e à sociedade. Ou, ainda, caracterizase como amalgamador das diversas práticas profissionais da instituição, ou seja, o cimento que realiza a justaposição adequada não só de cada profissional, como também de suas ações ${ }^{(15: 1015)}$.

\section{Assistência curativa e individual}

A ESF propõe um novo modelo de atenção e da organização do trabalho em saúde, que requer do profissional, além da competência clínica, o desenvolvimento de estratégias que promovam a saúde da população adscrita, mediante ações de atenção integral que tenham como foco a família.

Os sujeitos desta pesquisa souberam descrever algumas atividades desenvolvidas pelo enfermeiro como encaminhamentos, ações de prevenção, grupos. Porém, se referiam, na maioria das vezes, a ações de cunho curativo e individual - o que se contrapõe ao foco da ESF, como se observa nas falas a seguir:

Ela faz... ela dá receita. Passa receita pra gente. Faz exame ginecológico, que é aquele exame de prevenção. E dá receita também quando... assim, quando não é remédio controlado ela dá receita. É isso. (U2)

Qualquer problema que a gente tem, a gente procura ele. Por exemplo: eu tô com a minha filha doente, ai eu quero passar, eu passo nele primeiro, pra depois passar no médico. Pra ele dar um encaminhamento. Na maioria das vezes, é isso. (U4)

O Ministério da Saúde do Brasil, por meio da Política Nacional de Atenção Básica, fixa as atribuições comuns a todos os profissionais das equipes, entre as quais se destacam: a realização do cuidado à saúde da população adscrita mediante ações de atenção integral, conforme a necessidade de saúde da população local, de modo a garantir a integralidade da atenção, com a promoção da saúde; busca ativa e notificação de doenças e agravos; participação nas atividades de educação permanente e na execução de outras ações e atividades a serem definidas de acordo com as prioridades locais ${ }^{(5)}$. O relato a seguir ilustra essa categoria:

O trabalho dela aqui...primeiro a gente vem marcar ficha, ai passa por ela pra depois chegar no médico. Ela não dá receita, ela não dá remédio, nem nada não. Tem que marcar ficha e depois ela vai e passa pro médico. Primeiro tem que passar por ela. (U1)

A partir dos relatos, observa-se que a assistência dos enfermeiros reitera a lógica da prática clínica, individual e curativa. Percebe-se que a consulta de enfermagem tem sido uma forma de aliviar a agenda do médico, com conotação prescritiva e foco no indivíduo, dissociando-o da dimensão familiar e social.

Entretanto, pode-se afirmar que este resultado não deve ser atribuído somente ao enfermeiro que presta assistência com enfoque curativo. Segundo estudo $^{(8)}$, os usuários têm uma preocupação voltada para o assistencial, a quem recorrer se algum problema 
ou agravo já se instalou, uma vez que canalizaram os aspectos relevantes da ESF para o "atendimento", "o posto de saúde". Tal estudo considera, ainda, que essa realidade resulta de um modelo curativo que predominou por décadas e que se perpetua, apesar da filosofia inovadora da ESF. Mudança no paradigma do setor saúde, proposta pela ESF, requer também mudança de costumes e valores culturais bastantes enraizados e complexos, o que não ocorrerá em curto prazo $^{(8)}$.

Não houve nos relatos registro da visita/atendimento domiciliar como uma atividade desenvolvida por enfermeiros. A visita da equipe de saúde, e aqui se inclui o enfermeiro, aos membros da comunidade, é um meio de aproximação entre o serviço e o usuário, uma vez que propicia a inserção da equipe no cotidiano das pessoas, identificando demandas, potencialidades e fragilidades das famílias, formando uma parceria de promoção, prevenção e terapêutica necessária ${ }^{(18)}$.

\section{Figura Benevolente}

Apesar de os usuários entrevistados saberem identificar o enfermeiro dentro da ESF, diferenciandoo dos outros membros da equipe, apontam que há sobreposição de significados quando configuram o trabalho do enfermeiro como caridade, atribuindo a estes a figura de benevolência.

O estabelecimento do vínculo entre a equipe de saúde e a comunidade foi uma das grandes conquistas trazidas pela ESF. Contudo, isso possui uma dupla face, com aspectos positivos, pois traz consigo uma relação de confiança e credibilidade, e negativos, podendo extrapolar os limites técnicos e profissionais, adentrando em espaços que exigirão do profissional habilidades pessoais, a fim de evitar exposições.

Os usuários atrelam ao enfermeiro a imagem de bondoso, acessível, e que está sempre preocupado com tudo aquilo que aflige a vida humana e disposto a resolver o problema de todos. Os relatos a seguir traduzem essa ideia:

Muito bom! Ele é bem recebido em qualquer lugar que ele vai. É bom! Pelo menos pra mim serve muito, sabe? (U4)

Ah! Muito bom! Bom mesmo! Eu gosto, viu? A gente gosta muito dela, né? Muito atenciosa. Trata as pessoas com carinho, né? De brincadeiras, né? Eé muito boa funcionária... (U6)
Uai! Eu...eu... eu acho que ela trabalha muito assim... ela tem muita atenção, né? (U3)

Há uma certa confusão entre a percepção do trabalho do enfermeiro com a sua maneira de lidar com o usuário. Enfermeiros são vistos como profissionais generosos, solidários e muito acessíveis. A construção desse tipo de imagem possui raiz e sentido na história da profissão, a qual era exercida pela vocação e dedicação cristãs, ou como penalidade pelos desvios de caráter ou morais, além da mística existente ao redor das mulheres que detinham o poder de cura na Idade Média. Contudo, essas imagens, apesar da evolução do comportamento e do perfil profissional, ainda apresentam resquícios no imaginário socioprofissional ${ }^{(15)}$. Não se está aqui fazendo apologia à desumanidade ou distanciamento na relação enfermeiro-paciente, questiona-se apenas esta sobreposição do pessoal ao profissional, e qual a resolubilidade prática disto no serviço diário do enfermeiro.

\section{CONCLUSÃO}

A Atenção Básica requer dos profissionais de saúde habilidades, muitas vezes não adquiridas durante a formação acadêmica. Assim, acredita-se que a desarmonia entre o trabalho desenvolvido pelos enfermeiros e o novo modelo de atenção proposto decorra da falta de preparo desse profissional, o qual não transferiu, de forma plena e adequada, o seu foco assistencial para o indivíduo como ser social, sujeito e objeto da saúde comunitária. Além disso, a inespecificidade do trabalho do enfermeiro, observada nos relatos dos usuários, pode ter sua origem na atuação dos próprios profissionais, que ainda "não se encontraram" dentro do trabalho da ESF, agregando a si funções e afazeres que não lhes são próprios.

A capacitação contínua destes profissionais é responsabilidade também das instituições de saúde; sugere-se que se promova a atualização de conceitos e a disponibilização de recursos aos enfermeiros de Saúde da Família deste município, para lidar com as questões sociais e técnicas inerentes a essa nova dinâmica de trabalho, além de esclarecer e permitir a delimitação do "fazer" do enfermeiro na assistência à comunidade.

Saber quem é o enfermeiro dentro da equipe de Saúde da Família torna-se relevante quando essa identidade expressa a definição do exercício da enfermagem em Atenção Básica, e não quando significa apenas "apontar" o enfermeiro da USF. Para isso, é preciso que 
se faça uma reflexão sobre a construção da identidade do enfermeiro e, a partir daí, efetivar mudanças para a reafirmação da sua essência profissional.

Portanto, a escuta do usuário possibilitou uma avaliação da atuação do enfermeiro em ESF no município, fomentando discussões que podem levar a melhorias na dinâmica do trabalho na comunidade.

\section{REFERÊNCIAS}

1. Brasil. Constituição da República Federativa do Brasil. Brasília: Senado;1988.

2. Marques D, Silva EM. A enfermagem e o Programa Saúde da Família: uma parceria de sucesso? Rev Bras de Enferm. 2004;57(5):545-50.

3. Ministério da Saúde (BR). Secretaria de Atenção à Saúde. Departamento de Atenção Básica. Saúde da família no Brasil: uma análise de indicadores selecionados: 1998-2005/2006. 2a ed. Brasília; 2008.

4. Cianciarullo TI. Compreendendo a família no cenário de uma nova estratégia de saúde. In: Cianciarullo TI, Gualda DMR, Cunha ICKO, Silva GT. Saúde na família e na comunidade. São Paulo: Robe Editorial; 2002. p. 17-37.

5. Brasil. Portaria n. 648, de 28 de março de 2006. Aprova a Política Nacional de Atenção Básica, estabelecendo a revisão de diretrizes e normas para a organização da Atenção Básica para o Programa Saúde da Família (PSF) e o Programa Agentes Comunitários de Saúde (PACS). Diário Oficial da União [Internet] 29 mar 2006 [acesso em 28 set 2009]. Disponível: http:/189.28.128.100/dab/docs/legislacao/ portaria_648_28_03_2006.pdf

6. Nascimento MS, Nascimento MAA. Prática da enfermeira no Programa de Saúde da Família: interface da vigilância da saúde versus as ações programáticas em saúde. Ciênc Saúde Colet. 2005; 10(2):333-45.

7. Turrini RNT. Resolutividade dos serviços de saúde e satisfação do cliente. In: Cianciarullo TI, organizadora. Saúde na família e na comunidade. São Paulo: Robe; 2002. p.102-22.

8. Aguiar ACS, Moura ERF. Percepção do usuário sobre a atuação da equipe de saúde da família de um distrito de Caucaia-CE. Rev Bras Promoc Saúde. 2004;17(4):163-9

9. Esperidião M, Trad LAB. Avaliação de satisfação de usuários. Ciênc Saúde Colet. 2005;10 Suppl: S303-312.

10. Turato ER. Tratado da metodologia da pesquisa clínico-qualitativa: construção teórico-epistemológica, discussão comparada e aplicação nas áreas da saúde e humanas. Petrópolis: Vozes; 2003.

11. Bardin L. Análise de conteúdo. Lisboa: Edições 70; 1977.

12. Aquino EML, Menezes GMS, Amoedo MB. Gênero e saúde no Brasil: considerações a partir da pesquisa nacional por amostra de domicílios. Rev Saúde Pública. 1992;26(3):195-202.

13. Giatti L, Barreto, SM. Situação do indivíduo no mercado de trabalho e iniqüidade em saúde no Brasil. Rev Saúde Pública. 2006;40(1):99-106.

14. Paschoalick RC, Lacerda MR, Centa ML. Gênero masculino e saúde. Cogitare Enferm. 2006;11(1):80-6.

15. Gomes AMT, Oliveira DC. A auto e heteroimagem profissional do enfermeiro em saúde pública: um estudo de representações sociais. Rev Latino-Am Enfermagem. 2005;13(6):1011-8.

16. Netto LFSA, Ramos FRS. Considerações sobre o processo de construção da identidade do enfermeiro no cotidiano de trabalho. Rev Latino-Am Enfermagem. 2004;12(1):50-7.

17. Ciampa A. Identidade. In: Lane STM, Codo W, organizadores. Psicologia social: o homem em movimento. São Paulo: Brasiliense; 1984. p. 58-75.

18. Vasconcelos AC, Moura ERF. Percepção do papel desempenhado pela enfermeira de um PSF: segundo a ótica do usuário. Rev Rene. 2003; 4(1): 9-16. 